\title{
An adaptive and resilient islanding approach for power system considering secondary collapses
}

\author{
Sanaullah Kaka ${ }^{*}$, Mingchao Xia ${ }^{2}$,Mazhar Hussain ${ }^{3}$,Ali Raza Meer ${ }^{4}$, Shubash Kumar ${ }^{5}$ \\ ${ }^{1}$ School of Electrical Engineering, Beijing Jiaotong University, Beijing China \\ ${ }^{2}$ School of Electrical Engineering, Beijing Jiaotong University, Beijing China; mchxia@bjtu.edu \\ ${ }^{3}$ School of Electrical Engineering, Beijing Jiaotong University, Beijing China; mazhar.hussain@bjtu.edu \\ ${ }^{4}$ School of Electrical Engineering, Beijing Jiaotong University, Beijing China; alirazameer@bjtu.edu \\ ${ }^{5}$ School of Electrical Engineering, Beijing Jiaotong University, Beijing China; shubashkumar2001@gmail.com \\ * Correspondence: sanakaka@bjtu.edu.cn
}

\begin{abstract}
The power system vulnerability leads to faults and the severity of the fault may lead to prolonged load-shedding. The power system needs to be configured in extreme failure scenarios for protecting the network from further contingencies and prolonged load-shedding. Distributed generation resources (DGs) can be useful to form intentional islands after faults to maintain the continuity of power supply to loads based on their weightage during faulty periods and to reduce overall load shedding duration. Power system is bound to collapses and secondary collapse in the formed island is possible. This research represents a novel method of impedance based path finding for intentional islanding, which adapts itself with the changes in the demands, DGs outputs or further severities during restoration period. In this adaptive islanding approach, network adjusts itself with the changes in either the load demands or renewable DGs outputs and rearranges the restoration plan by curtailing or adding some of the loads through controllable switches. Further a secondary collapse in the existing island is studied by injecting multiple faults at various positions of the network to validate the system resilience to cope with severities. A short-term load forecasting approach is used to predict changes in load demands and variations in DG outputs during the islanding scheme. During the restoration period, these variations are tracked and the islands are modified accordingly. In order to minimize the overall generation cost by using less fuel, an economical approach is used in the selection of controllable DGs. The proposed approach is formulated as a multi-objective, that incorporates several operational constraints and simulation is carried out using the modified IEEE 69-bus distribution system to assess the efficacy of the proposed model.
\end{abstract}

Keywords: Adaptive Island, Minimum spanning tree, Load forecasting, Controllable switches, Distributed generations

\section{Introduction}

After a major natural disaster occurs, most customers are affected because of disruption in feeders for the power distribution. Major catastrophe shatters the power distribution system (PDS), power facilities may be destroyed and numerous faults are inevitable [1] as a result of which utility power may not be available due to anti-islanding protection [2], and independent DGs are disconnected from the grid, allowing the end user to lose power. Improving resilience requires mechanisms to restore distribution networks quickly utilizing all available resources. In this case, local power resources in the PDS can be utilized to resume power supply to the important loads and decrease losses. Distributed power sources such as micro-turbines, energy storage (ES), and Photovoltaic (PVs) are considered worthwhile resources for service recovery [3].

Earlier researchers focused on scheming expert systems and heuristic search methods $[4,5]$ for restoration problems. Algorithms such as Soft computing, including genetic algorithm (GA), particle swarm optimization, simulated annealing, and fuzzy set approaches, have also been proposed [6,7]. Mathematical programming for an unbalanced distribution system has been proposed for service restoration in $[8,10]$.

Restoring the distribution system using active distribution network methods were also proposed [11, 14]. For example, restoration algorithms based on spanning tree search were proposed to restore critical loads in [11, 12]. Some suggested methods use DGs to restore loads after an extreme case, splitting the distribution system into many smaller micro-grids [13], [15, 16]. These methods, however do not consider tie switches, limiting them inapplicable to the DSR problem. 
The resilient micro-grid formation of PDS following a natural disaster was reviewed in [17]. Load restoration was accomplished by micro-grids, while load priority, DGs output forecasting, and load-shedding was not in sight.

By developing multi-agents in the [18], power system restoration with multiple DGs was suggested. There was no analysis of the load variability and uncertainty of DGs. In terms of optimal power distribution for the islands, uncertainties of loads and DGs during the partition period are important factors. Different approaches have studied the uncertainties of the power system. A two-stage robust optimization model for the distribution network reconfiguration problem with load uncertainty was proposed by the authors in [19]. In [20], the problem of substation time-varying loads and uncertainty has been studied. The heuristic method of interval analysis is used in [21] to demonstrate the effect of uncertain parameters on the results of the reconstruction. The affine arithmetic approach for the assessment of voltage stability was used in [22]. A range arithmetic method for power flow problems like interval data was proposed by the author in [23]. Under the transmission line parameter uncertainties, the synchronized phasor measurement data and state variables were used in rectangular forms to perform the state estimate in [24].

The stochastic micro-gird operating framework under the uncertainties of load, generation and contingencies is described in [25]. A two-stage optimal controlled islanding and restoration scheme, along with different loads, was proposed by authors in some other studies, such as [26]. DGs are divided into two groups in [27] and only DGs with battery-power storage systems are considered controllable. The goal of island operations in [28] is to minimize power mismatches, while [29] is to pay more attention to the limits of power flow.

The authors have not discussed the adaptability and resilience of the restoration scheme with the secondary collapses in the islands. Islanding approach to respond the changes in loads or DGs also need considerable attention to provide adequate flexibility for optimum supervision, sustainability, and self-healing functions of the power system. In addition, the cost-effective selection of controlled type DGs (Diesel) in the islands with varying demands is also not focused. To address these issues of islanding-based restoration schemes, an ideal approach for adaptable islands to deal with the uncertainties and optimal scheduling of DGs throughout the restoration period is proposed. The overall contributions of the proposed approach are demonstrated as follows:

- Primary Island is determined using novel path finder coefficient using the search-based approach at the beginning of the restoration scheme. Graph theory (Prims algorithm) is the search-based approach used to form the islanding structure. Changes (load changes and variations in the generation of renewable DGs) are tracked during the second stage of the restoration scheme and the islands are modified accordingly. At some point of islanding scheme multiple faults are injected and adaptability of island to cope with such severity is dealt. Controllable switches are used to execute the switching operations to ensure the islands are adaptive to the changes. Adjustment of the island is in the form of either expansion or curtailment of the loads depending upon the load demands and generation capacity difference. This expansion or shrinking of the islands is accomplished through controllable switches.

- A cost-effective power sharing framework for controlled DGs (Fuel powered DGs) is proposed, in which DGs are chosen for the islands, taking into account the minimum generation cost factor. DGs are categorized on the basis of the minimum cost per $\mathrm{kW}$ of generation and the selection of economic DGs depends on the difference in load demand/power generation and the available generation of renewable DGs.

The rest of this paper is organized as follows. Section 2 describes the restoration strategy. The problem formulation is described in section 3. Section 4-8 are about island formation, case studies, results discussion, comparison, and conclusion, respectively.

\section{Restoration Planning}

This section includes the framework of the proposed approach, implementation of graph theory and description of some new variables which will be used in the decision-making process of the proposed restoration framework.

\subsection{Restoration Framework}

When PDS is isolated as parts and divided by natural disasters into unsupplied islands, then the restoration of power supply cannot be assured by the conventional changing topology style restoration process. However by means of switches and DGs, PDS may be purposely divided into single or multiple islands to continue to supply power to priority loads, while meeting different island constraints. A DG-based island is an autonomous device promising a local group of small DG units and loads. 
Figure 1, shows the intentional islanding of PDS, which is formed by the connecting distribution feeders and DGs. In an effective restoration scheme, number of tie switches and sectionalizing switches are activated to restore the loads of outage area. The combination of these switches will lead to multiple open loop configurations (radial configurations) to restore the load.

There is a need for wise decisions to carry out switching operations for restorations in order to run the restored PDS radially. Furthermore, because the time taken for the recovery process depends on the number of switching operations, the number of switching operations should be kept to a minimum. The IEEE Standard 1547-2018 standards supports the idea for DG-based islanding. In extreme events, DGs can be utilized to increase the restoration of priority loads by forming intentional islands.

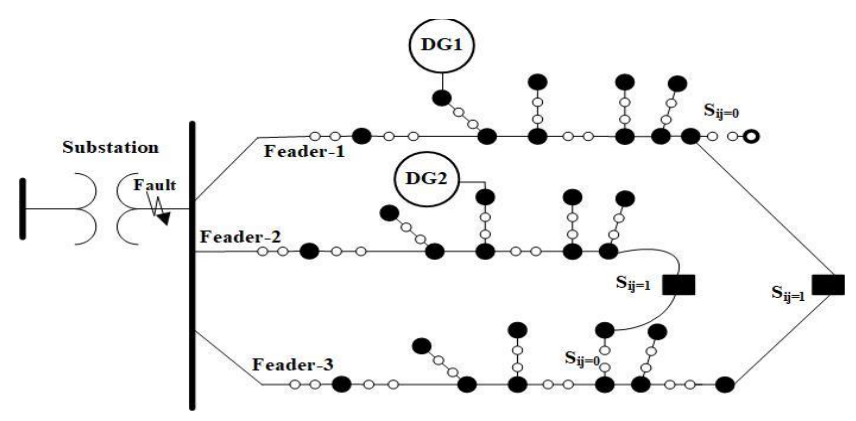

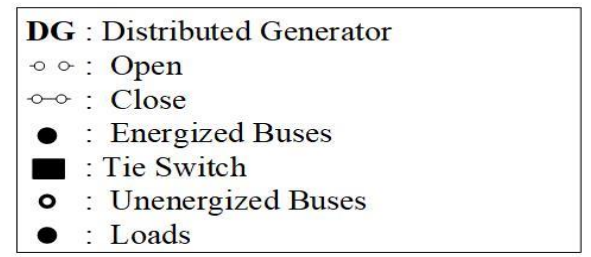

Figure 1. Understanding of intentional islanding and switching operations

\subsection{Graph theory implantation on Distribution network}

The distribution network can be represented as a directed or undirected graph by converting its structure into a graph. An undirected graph has no direction between the two vertices associated with each line, or its lines, or directed, meaning there is a distinction between one node and another. There have been many graph theories used to optimize the power system, and each one has its purpose and benefits. In this approach, Prim's minimum spanning tree is implemented to simplify the power system issues after setbacks have devastated it [30].

In the proposed islanding-based restoration problem, certain variables are introduced and are explained below:

a) A binary variable $S_{\mathrm{ij}}$ is introduced with each line section including switches, where 0 value of $S_{\mathrm{ij}}$ indicates switch is opened, and 1 indicates closed switch joining buses $\mathrm{i}$ and $\mathrm{j}$.

b) Status for bus/node energization is represented with $B_{n}$, it will be either 0 or 1 .

c) To know if the load is restored through the switch or remains disconnected is presented by Lsn. It is also represented with values 1 or 0 .

d) DG status 1 or 0 represents connected/ disconnected to island.

\section{Problem Statement}

In this section we explain a mathematical formulation of islanding-based service restoration using all available resources, including DGs. This section is divided in three sub-sections. Sub-section one presents mathematical approach for objectives subsection two explains about the conditions to satisfy the objectives during islanding periods whereas third subsection is about problem formulation of the constraints used in this novel approach.

\subsection{Objective functions}


This approach is formulated as multi-objective consisting of the following main objective functions:

- Minimum Load Shedding: The first objective function is to minimize the total amount of loads to be shed. This objective is described as follows:

$$
\min \left(\sum_{i=1}^{n} v_{i}\left(P^{D G}-P_{i}^{L D}\right)\right.
$$

$P^{D G}$ is the power supplied to load by DGs and $P^{L D}$ is power demand of bus $i$, and $v i$ is the weight coefficient of $i$ th bus.

- Minimum Switching Operations: The second and most important objective of proposed approach is the minimum switching operations during islanding periods. Formulation is given below:

$$
\min \left(\sum_{(i j) \in S S}\left(1-S_{i j}\right)+\sum_{(i j) \in T S} S_{i j}\right)
$$

Where $i$ and $j$ are the buses SS are sectionalizing switches and TS are the tie switches.

- Minimum cost of generation: This objective plays a vital role to save fuel cost where economical concerns are at high. This function is described below:

$$
\min \left(\sum_{i=1}^{n} \alpha^{C D G}{ }_{i}^{D G}{ }_{i}+\sum_{i=1}^{n} \beta^{U D G}{ }_{i}^{D G}{ }_{i}\right)
$$

Where $\alpha^{C D G_{i}}$ and $\beta^{U D G_{i}}$ are the cost coefficients of the ith controlled type DGs (diesel) and uncontrolled type DGs (renewable) respectively. Note that values of these coefficients may vary with each DG.

\subsection{Set of conditions for Objectives}

This approach is formulated as multi-objective consisting of the following main objective functions:

- Minimum load shedding: Power balancing method is used to determine the total loads to be sheds. In case of load variations and DGs output uncertainties, hourly load demands and DGs outputs are utilized to make the islanding scheme adaptive and sustainable.

- When the minimum amount of load to be shed is known, the next step is to optimize the use of available resources to restore loads while concentrating on the islands' minimum losses.

- Loads to be restored are selected based on their weightage and are carefully chosen having lowest weight coefficients.

- Minimum switching operations: If two loads of high priorities are to be restored, one of them is with switches and other non-switchable, then priority is given to non-switchable load and if there is enough capacity left to restore switchable load, then it can be supplied power or left shedded in case if power is not sufficient.

- Loads with switch can be picked up if the connected bus with it is already energized by nearby DG.

- Non-Switchable load is always picked up if the corresponding bus in the path is energized.

- If the line is selected for energization using [31], having a switch then the buses connecting the line must be energized.

$$
S_{i j} \leq B_{i}
$$

- If the line with load is non-switchable and connecting buses to it are energized, then that line must be energized.

$$
L_{s n} \leq B_{n}
$$

- Minimum cost of power generation: Minimum cost of generation of the power is dependent on the selection of suitable fuel type DGs which consumes less fuel compared to other DGs available for selection.

- There are multiple uncontrolled DGs utilized for islanding scheme. Each of them have different characteristics and cost of generation. This will be described in the later sections. 
- If all of the renewable DGs are unavailable and there is need to use all the uncontrolled DGs then $\alpha^{C D G}$ becomes 1 and $\beta^{U D G}$ equals to zero. In this case all of the controlled DGs need to be utilized depending upon the load demands requirements.

- If all the uncontrolled DGs are generating full capacity then $\beta^{\text {UDG }}$ for every renewable DG becomes 1 . In this case depending upon $P^{D G_{-}} P L D$, a suitable uncontrolled DG need to be picked up depending on its generation cost value.

- If only one uncontrolled DG is picked up, then $\alpha^{C D G}$ for that particular DG is 1, and coefficients $\alpha^{C D G}$ for remaining unselected, uncontrolled DGs equal to 0 . Similarly if only one renewable DG is chosen then $\beta^{U D G}$ for selected DG becomes one and for others equal to zero.

\subsection{Constraints}

This approach is formulated as multi-objective consisting of the following main objective functions:

DG capacity constraints: DG capacity constraints states that the amount generated by DGs should be either greater or equal to the load demands. Load demands can't exceed the generation capacity of DGs.

$$
\begin{gathered}
S_{i j} P_{i, H}^{D G} \geq P_{i, H}^{L D} \\
S_{i j} Q^{D G}{ }_{i, H} \geq Q^{L D}{ }_{i, H}
\end{gathered}
$$

Equations (6) and (7) represent the active and reactive power of DGs and loads Where $P \mathrm{DG}_{\mathrm{i}, \mathrm{H}} \quad$ is the capacity of $i$ th DG at time $H$ and $P L D_{i, H}$ is the load demand of $i$ th bus at time $H$.

It is assumed that DGs can provide active and reactive power in a permissible range. Mathematically is can be shown as:

$$
\begin{aligned}
& P_{i, H}^{D G, \text { min }} \leq P_{i, H} \leq P^{D G, \text { max }}{ }_{i, H} \\
& Q^{D G, \text { min }}{ }_{i, H} \leq Q_{i, H} \leq Q^{D G, \text { max }}{ }_{i, H}
\end{aligned}
$$

Equations (8) and (9) describe the active and reactive power limits of the DGs. Where $P^{D G, m i i_{1, H}}, Q^{D G m i i_{i}, \mathrm{H}}$ are the minimum active and reactive power limits of DGs, and $P^{D G, m_{i} x_{i, H}}, Q^{D G, m a x} x_{i, H}$ are the upper limits of DGs.

Electrical network constraints: Power flow constraints in [32] are used in this proposed study. It is a very powerful method and it converges quickly to near the solution. This property is particularly useful for power system applications because it is easy to get an initial guess close to the solution. Power system should maintain the network constraints. Power flow constraints are given below:

$$
\begin{gathered}
\sum_{i=1}^{n} D G_{n} P_{i, H}^{D G}-\sum_{i=1}^{n} S_{i j} P^{L D}{ }_{i, H}=u_{i, H} \sum_{i=1}^{n} u_{j, H} Y_{i j}\left(\cos \theta_{i}+\operatorname{Sin} \theta_{i}\right) \\
\sum_{i=1}^{n} D G_{n} Q^{D G}{ }_{i, H}-\sum_{i=1}^{n} S_{i j} Q^{L D}{ }_{i n, H}=u_{i, H} \sum_{i=1}^{n} u_{j, H} Y_{i j}\left(\sin \theta_{i}+\cos \theta_{i}\right) \\
B_{n} u^{\min _{i, H}} \leq u_{i} \leq B_{n} u^{\max _{i, H}}
\end{gathered}
$$

Where $Y_{i j}$ is the admittance of the line, $u_{i}$ is the voltage magnitude of the bus $i, \theta$ is the admittance angle, and $u^{\text {min }}$, $u^{\max }$ are the lower and upper voltage boundaries respectively. Equation (10) calculates the active power demand of the node and (12) represent he reactive power of the node in the network. Voltage limits are presented in (13). The voltages 
of each bus should be within the limit. According to the standards of ANSI C $84, u^{\min }$ is set to 0.95 and $u^{\max }$ is 1.05 respectively.

Network topology constraints: Another significant aspect that must be tackled during the islanding system is the constraints of radiality. Switching operations of the islanded network need to be planned sensibly, so that the radiality of the network should also remain intact. To maintain the radiality if the network, the final network should not include loops in it. In the proposed algorithm, the final network doesn't have the loops or cycles in it as it goes radially. It's formulated as below:

$$
\sum_{b r} \mathrm{e}_{b r}=V-1
$$

Where $e_{b r}$ is the number of branches, $V$ is the number of nodes. This means that, for the radiality of the network to remain intact number of branches should be equal to number of nodes minus one.

DGs merging and coordination process: In the proposed restoration scheme at the start of the island formation a random node is picked up which is a DG node. This DG is the root or parent node. There are multiple DGs installed at various feasible locations. Few DGs are diesel type and are called controlled DGs and other renewable DGs are considered uncontrollable. If any controlled DG is picked up in the single island along with renewable DGs it will be a parent DG and all renewable DGs will act as slack DGs. If the proceeding node is a load node then power of the island will be deducted, where as if the next node is a DG node, them both DGs will coordinate as parent-slack node in the single island and powers will be merged to the total capacity of the island. By doing so multiple different types of sources will coordinate together and resulting island will be a single and large island. Coordination of the DGs adds the support to the idea of minimum load shedding. Mathematically DGs coordination in the island is presented as follows:

$$
\begin{gathered}
\sum_{i=1}^{n} P_{i}^{\text {Island }}=P_{i+}^{I G} P_{i}^{D G} \\
\sum_{i=1}^{n} P_{i}^{\text {Island }}=P^{I G}{ }_{i}-P^{L D}{ }_{i}
\end{gathered}
$$

Where $P^{I s l a n d}{ }_{i}$ is the total island power at node $i_{1,} P^{I G}{ }_{i}$ is initial generation capacity of the island when first random node is added to the island i.e. the initial DG power at the start of the island. Equations (14) and (15) represent the addition of the powers of the island in case of coordination of the DGs and power deduction with the integration of the load node to the island respectively.

\section{Island formation procedure}

In this study, a new weight coefficient $v$ is introduced as a restoration path finder. Its defined as impednace bewteen nodes divided by the priority and demand of the node. find the optimum restoration path. This path finder helps to find low impedance path along the restoration time, which not reduces the losses but helps maximize the optimal use of avaialble resources. After the major faults restoration process startrs as described below:

- A parent node, which is a DG node, is initially picked up at random. The scheme progresses on the graph (distribution network) by selecting the adjacent node. Selected DG at the start is the first source of resuming power to priority loads.

- Nodes are assigned the priorities of 100, 10, and 1 . The highest priority nodes are level-1 loads, which are set to value of 100, whereas level-2 and level-3 loads are given 10 and 1, respectively.

- Nodes with zero load demand are combined with their adjacent nodes to make the network simpler. 
- With the addition of a new node to the island, the remaining power of the island is updated by subtracting the node load demand from it.

- If the newly added node already exists in a previous island, it means that the two islands are now connected and should be merged. Therefore, all nodes of the previous island are also added as visited nodes.

- The algorithm keeps working until all of the DG power is utilized. At each node, load flow analysis is performed using (6)-(13) to make sure the island is stable and within limits.

- The concluded island is saved in an array, and the next island works by starting at step (i).

- As fault repair time is considered to be slightly longer, after the initial island is accomplished, the shape of the initial island can change before the fault is repaired depending on DGs output variations and load demands. Some of the loads may be added to the island or curtailed from the island using switching operations depending on the variations of the load demands and DGs output over the span of faults. The Flowchart of the islanding scheme is shown in Figure 2.

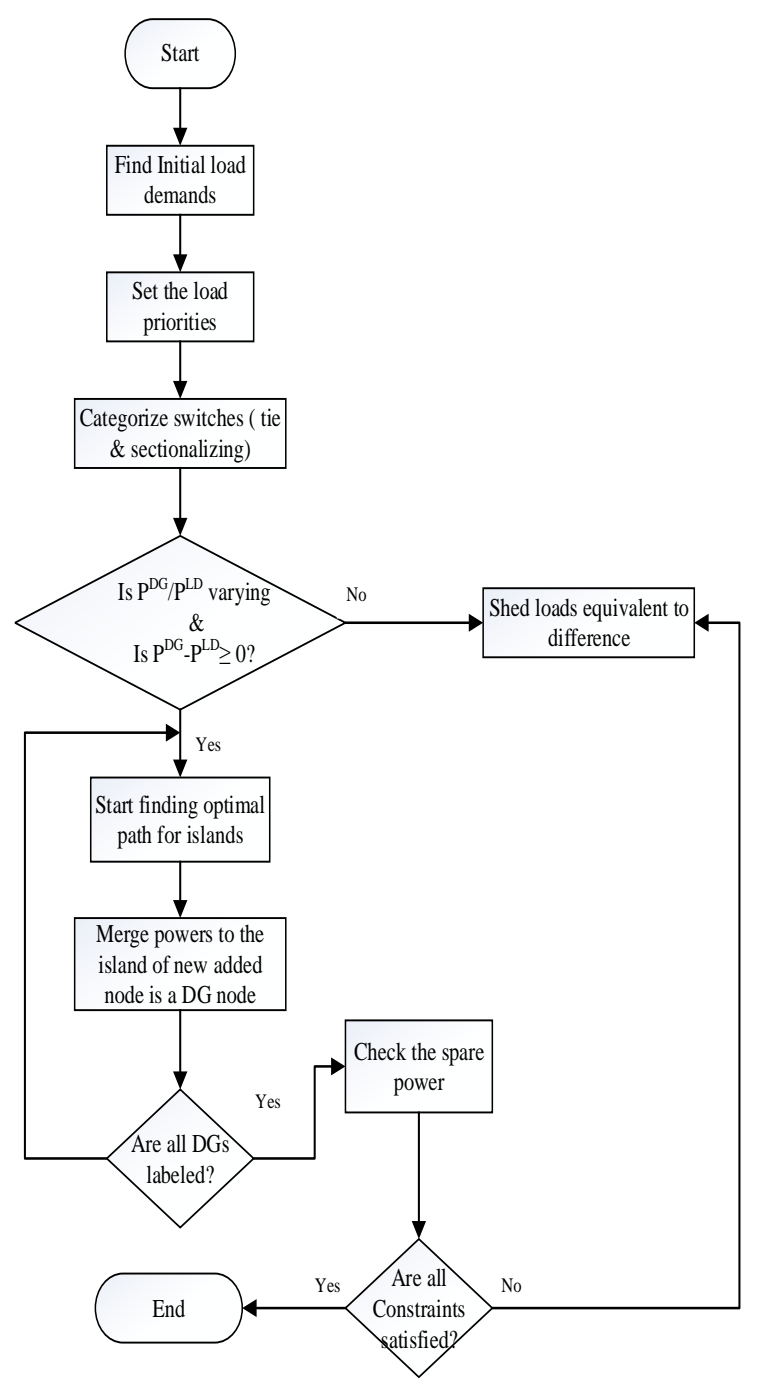

Figure 2. Flow chart of Proposed islanding scheme 
Table 1. Outputs forecast of renewable DGs

\begin{tabular}{ccccccccc}
\hline Hours & 1 & 2 & 3 & 4 & 5 & 6 & 7 & 8 \\
\hline DG-1 & 0 & 0 & 0 & 0 & 0 & 0.003163 & 0.011639 & 0.020625 \\
DG-3 & 0 & 0 & 0 & 0 & 0 & 0.024798 & 0.030638 & 0.087205 \\
DG-5 & 0 & 0 & 0 & 0 & 0 & 0.002422 & 0.008473 & 0.014218 \\
\hline Hours & 9 & 10 & 11 & 12 & 13 & 14 & 15 & 16 \\
\hline DG-1 & 0.02693 & 0.032469 & 0.034865 & 0.035032 & 0.033872 & 0.029408 & 0.023386 & 0.015467 \\
DG-3 & 0.166804 & 0.231123 & 0.263251 & 0.264447 & 0.248669 & 0.211154 & 0.167838 & 0.118394 \\
DG-5 & 0.01972 & 0.021399 & 0.02621 & 0.026458 & 0.025097 & 0.022493 & 0.017724 & 0.012042 \\
\hline Hours & 17 & 18 & 19 & 20 & 21 & 22 & 23 & 24 \\
\hline DG-1 & 0.007644 & 0.001714 & 0 & 0 & 0 & 0 & 0 & 0 \\
DG-3 & 0.063859 & 0.01911 & 0 & 0 & 0 & 0 & 0 & 0 \\
DG-5 & 0.006372 & 0.001763 & 0 & 0 & 0 & 0 & 0 & 0 \\
\hline
\end{tabular}

\section{Testing and verification}

There are three uncontrolled DGs (PV type) and three controlled DGs (Diesel type) used in this study. Amongst all three controlled type DGs, DG-4 is a new model DG and its cost of generation capacity is lower than DG-2 and DG6. Whereas DG-6s generation cost is lower than DG-2 i.e. (DG-2>DG-6>DG4). A mathematical model is presented which helps to select suitable DG during islanding time. Suitable selection of controlled DGs during islanding-based restoration will help reduce generation cost per $\mathrm{kWh}$ of the power.

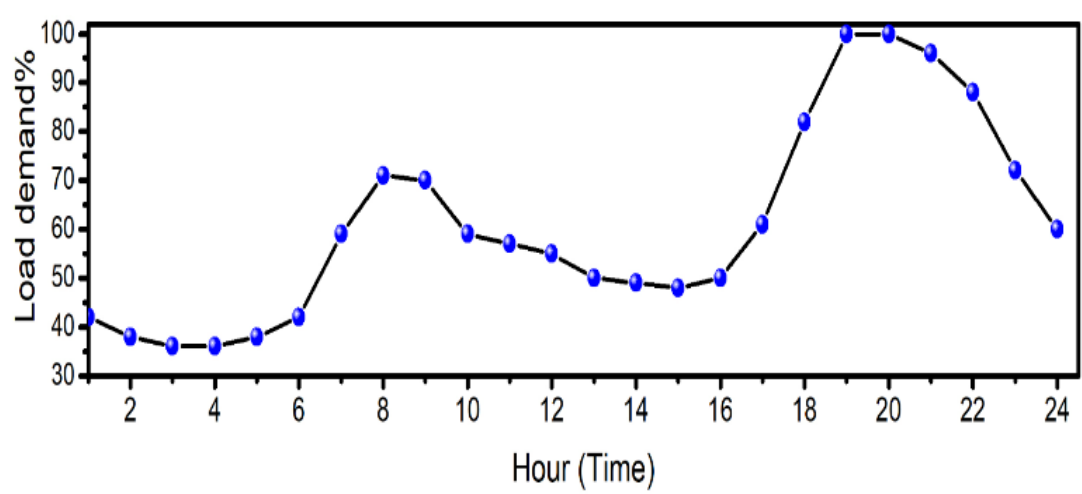

Figure 3. Daily load demands curve

The fault is presumed to start at hour-13 and takes approximately 7 hours to repair it and restore the supply of the grid. The curve of daily load demands shown in Figure 3 is taken from a specific summer/fall season graph [35]. It can be seen that over the fault length and islanding time, load demands and DG-1, DG-3, DG-5 generation capacity varies. The 24-hour output forecast for uncontrolled DGs is taken from [36] and is provided in Table 1. The restoration plan of DGs-based islanding systems is validated using Prim's MST technique for hours 13.00 to 17.00.

The proposed approach is implemented on the IEEE 69-bus distribution. The single line diagram of the modified IEEE 69-bus is shown in Figure 4. Total active load demand is 3.802MW [34], whereas DGs location, capacities are given in Table 2.

For case studies, it is presumed that the power restoration scheme can only be completed through the DGs connected at the different network nodes. If any of the linked DG fails due to unpredictable weather or PV type DGs do not generate sufficient output power in the evening hours, then the remaining DGs will be used for the restoration scheme. The resilience of the power system and efficiency of the island formed using the proposed study is validated further exposing the network to additional failures, when, due to any technical difficulties or due to weather problems, one or more PV type DGs stop sharing power with the island. Due to economic reasons, it is impossible to bring new controlled type DGs in case of failures. 


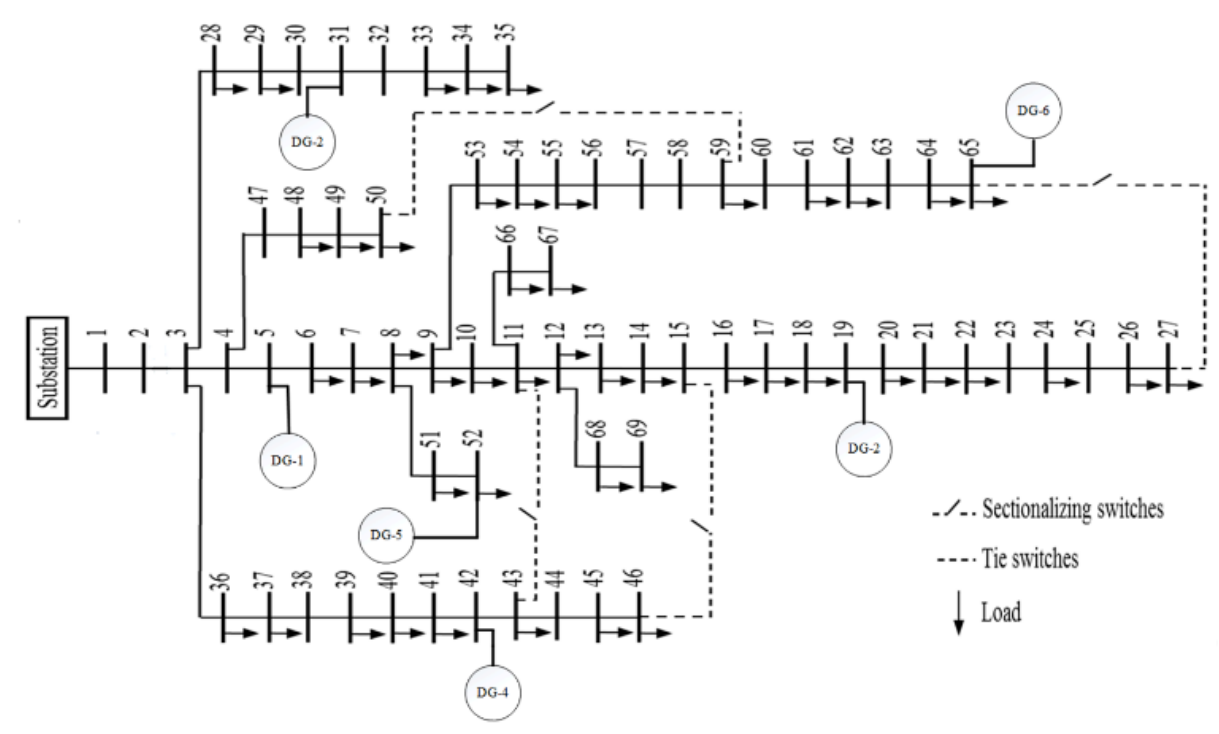

Figure 4. Modified IEEE 69-bus test feeder

The proposed Prim's algorithm is developed in MATLAB using Matpower system Toolbox and implemented on a modified IEEE 69-bus system. Two case are under observation to check single islanding formation. In first scenario the main grid is disconnected from the network in the event of a major fault between nodes 2 and 3 , and in second case multiple faults are injected to network to investigate the response of the proposed islanding scheme under severe contingencies.

Table 2[37]. Placement of DGs and their capacities

\begin{tabular}{llll}
\hline DG & BUS No. & DG TYPE & Generation Capacity (MW) \\
\hline DG1 & 5 & Uncontrollable (PV) & 0.05 \\
DG2 & 19 & Controllable (Diesel) & 0.2 \\
DG3 & 32 & Uncontrollable (PV) & 0.38 \\
DG4 & 42 & Controllable (Diesel) & 1.7 \\
DG5 & 52 & Uncontrollable (PV) & 0.04 \\
DG6 & 65 & Controllable (Diesel) & 0.1 \\
\hline
\end{tabular}

\section{Results}

In this approach DGs coordination is implemented along with tie switch to form single islanded networks to restore more loads and reduce load shedding. Thus, tie switches can be useful in restoring critical loads by providing added operational flexibility.

The island formed during the entire restoration scheme period is shown in Figures 5-9. In Figure 5 the initial island can be witnessed with zero load shedding and all loads are met as the island's generation capacity is greater than demand. With rising demands and declining generation capacity of renewable DGs, the shape of the island keeps changing, but it continues to maintain itself and prevent collapses due to its adaptability to cope the changes as can be seen in Figures.6-8. In hour 14 only bus 61 is curtailed, where as in hour 15, 16 total load of $57.82 \%$ and 56.31 percentage is restored. In the later hours nearly similar load percentage of load is curtailed, which is nearly $40 \%$ because renewable DGs generation have reduced. 


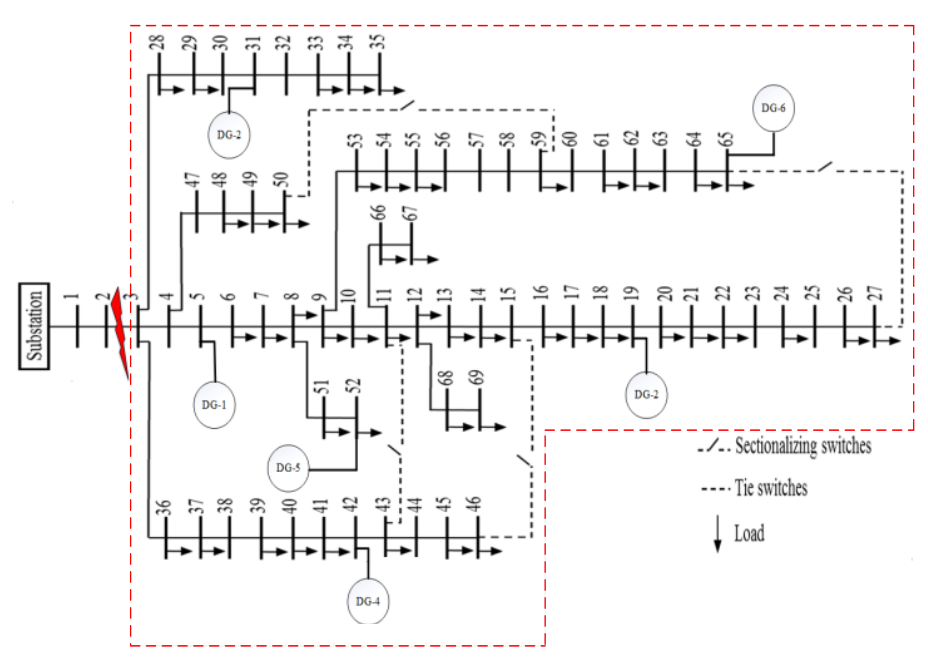

Figure 5. Initial Island

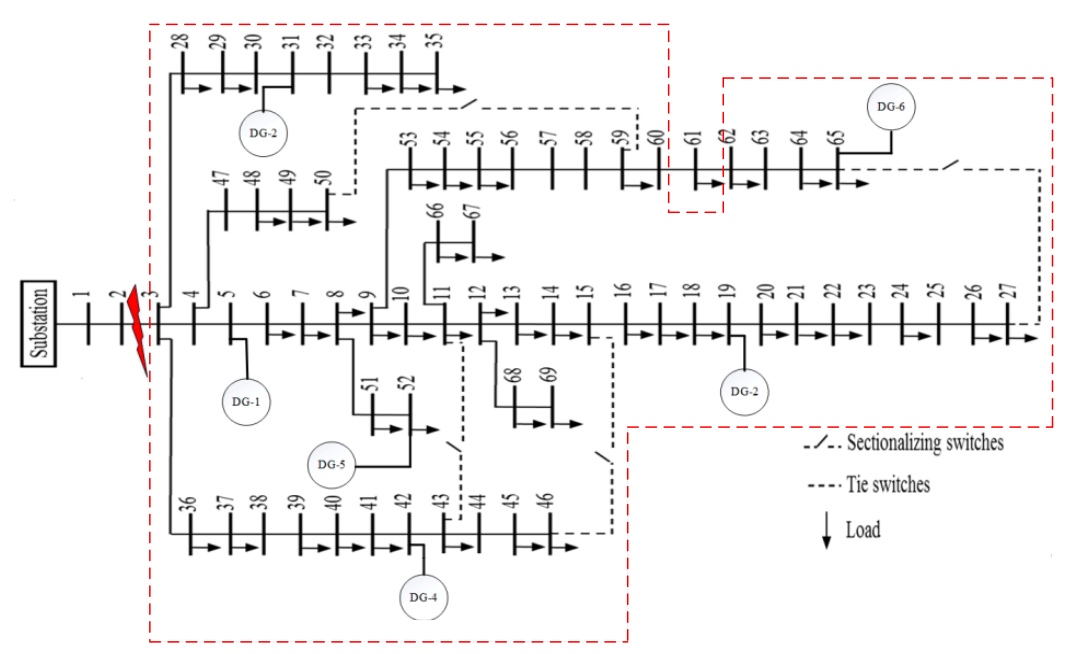

Figure 6. Adaptive mode-1 of island with uncertainties

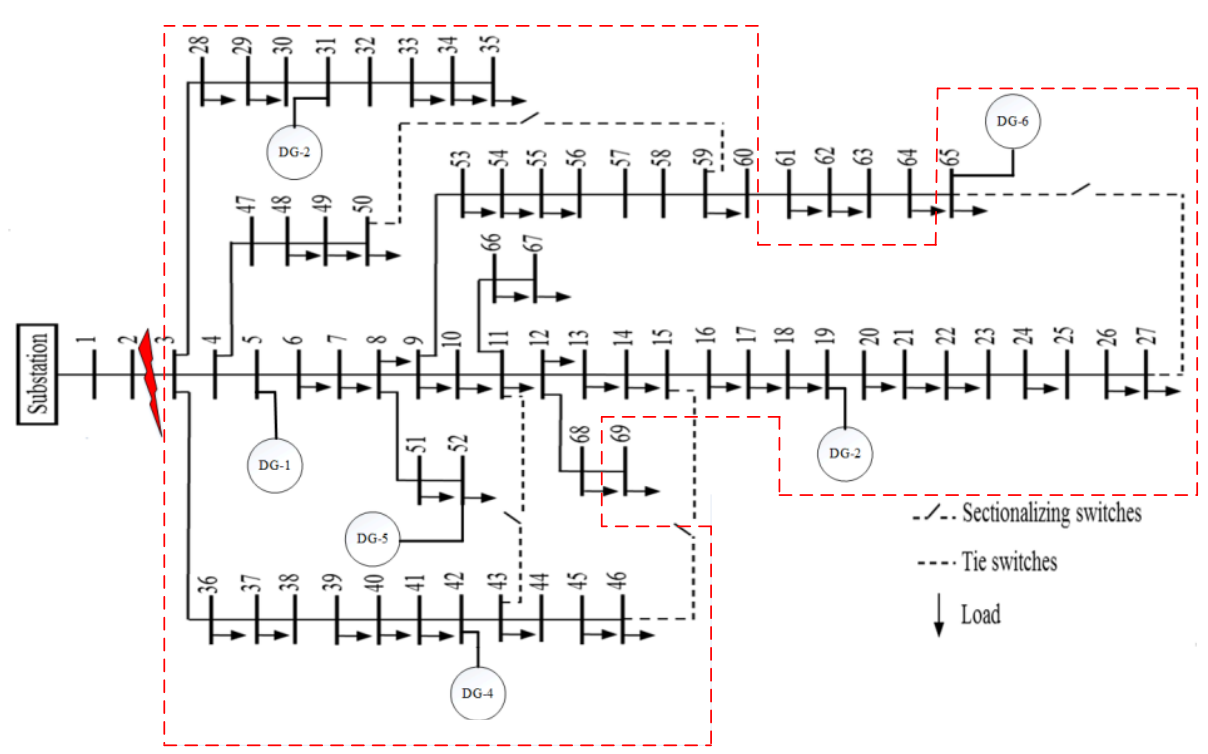

Figure 7. Adaptive mode-2 of island with uncertainties 
Due to the evening hours of the day the island in hour 19 must suffer the absence of all renewable DGs, but at the same time the load demand has also decreased, so the island adapts to changes and almost 73.4 percent of the load is restored and the shedding of the load is minimized as final shape of the island is shown in Figure 9. It is clear that a single island is formed initially and it is maintained as a single island through proper switching operations in later hours. As load demands increases, the nodes with highest demands has to lose power, so switches 60-61 \& 60-62 are closed. As demand keeps climbing with little decrease in the output power of DGs, further low priority loads have to be cut-off by switching off 60-61, 64-65 \& 68-69. In hour 16 renewable power further decreases due to low sun light intensity and as a result further low priority loads are cut-off by switching off 32-33, 60-61, \& 64-65. In the hour 19, all of the renewable DGs no more share their power, and this situation forces the island to shed some of the high priority loads by allowing some switching operation of 3-28,47-48. During whole island process tie switches 11-43, 15-46, 27-65 \& 50-59 are forced to remain close. Allowing tie-switches to remain on during the process help the island maintain its adaptability to variation of load demands and DGs output. Keeping the tie-switches close not only assist DG coordination but it also helps minimize switching operations. The other benefit of merging DGs power and allowing tie switches to remain closed while assisting single island is that DGs power is optimally consumed and no surplus power is left. Also over all power loss is reduced in the island. Combining the power of DGs and allowing tie switches to remain closed while assisting one island is that the power of DGs is optimally consumed and that there is no surplus power left. On the other hand, power losses are also minimized over all. Figure 10, shows the power losses during islanding period is lower than the initial loss.

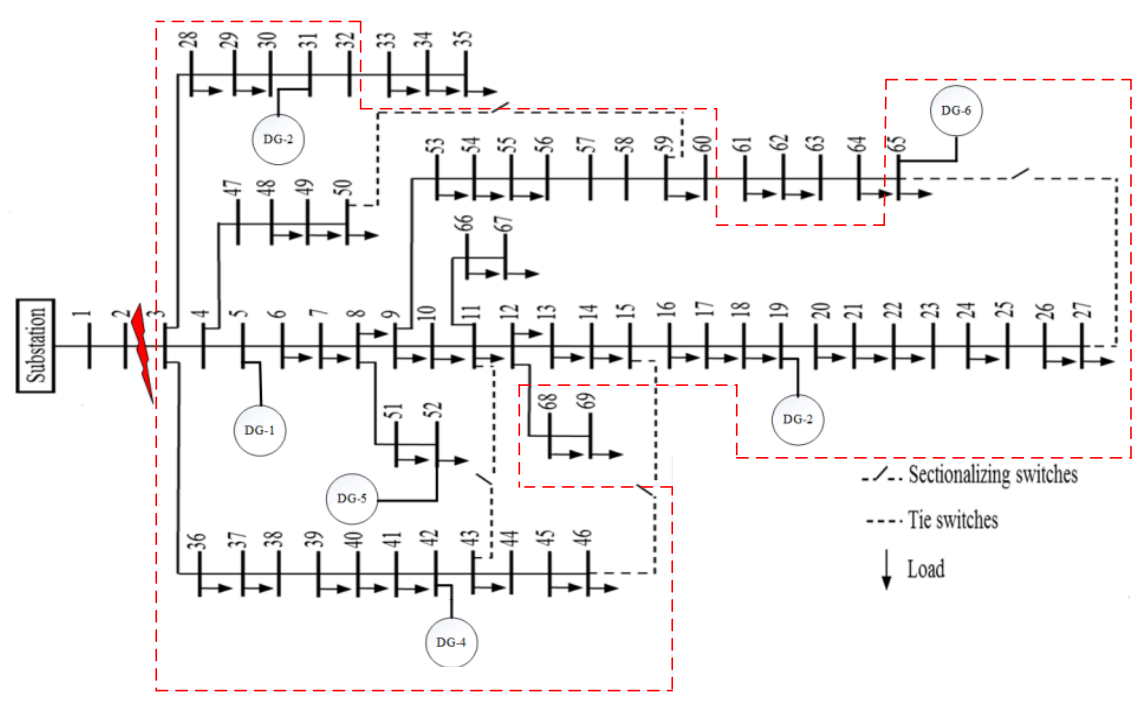

Figure 8. Adaptive mode-3 of island with uncertainties

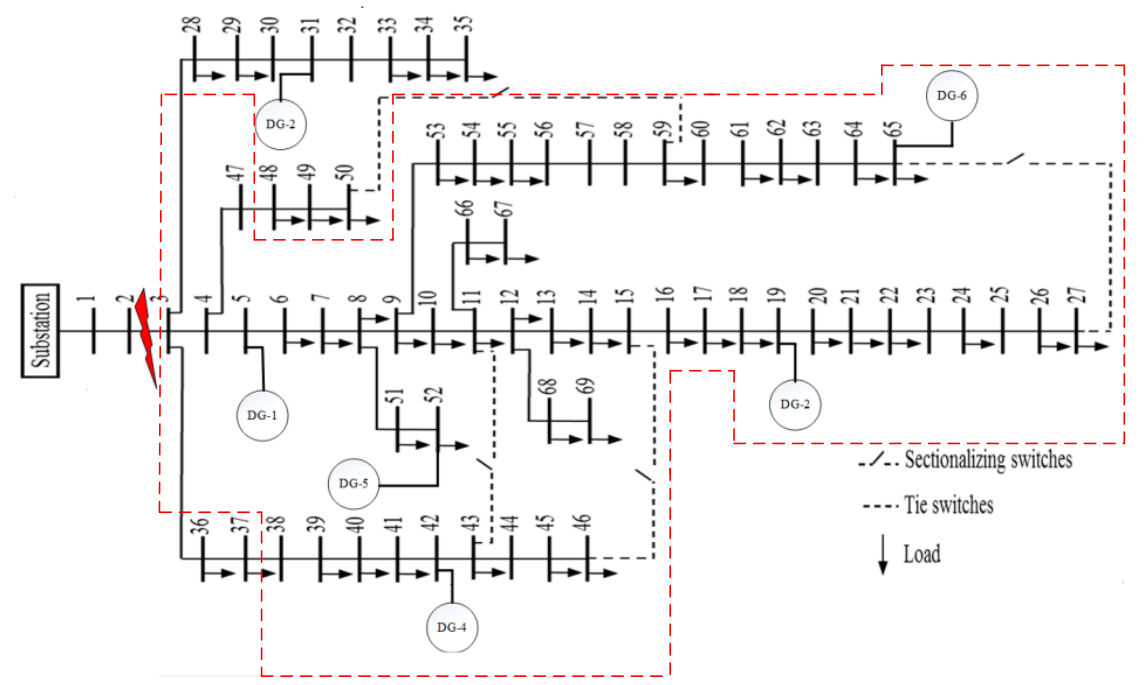

Figure 9. Final shape of the island 
The 24-hours economical plan for DGs selection is shown in Figure11. Amongst all three controlled DGs, DG4 has the highest capacity but lowest fuel cost per kilowatt of generation. Table shows that during initial hours only DG4 is considered as at that time renewable DGs can't generate any power, so it would be economical to only use DG4. For hours 6 \& 11-16, when demand is lower than generation capacity, all renewable DGs along with only single controlled type DG are utilized. The difference of load demands and DGs capacity is continuously monitored to check whether it is possible to bring in or disconnect the controlled DGs.

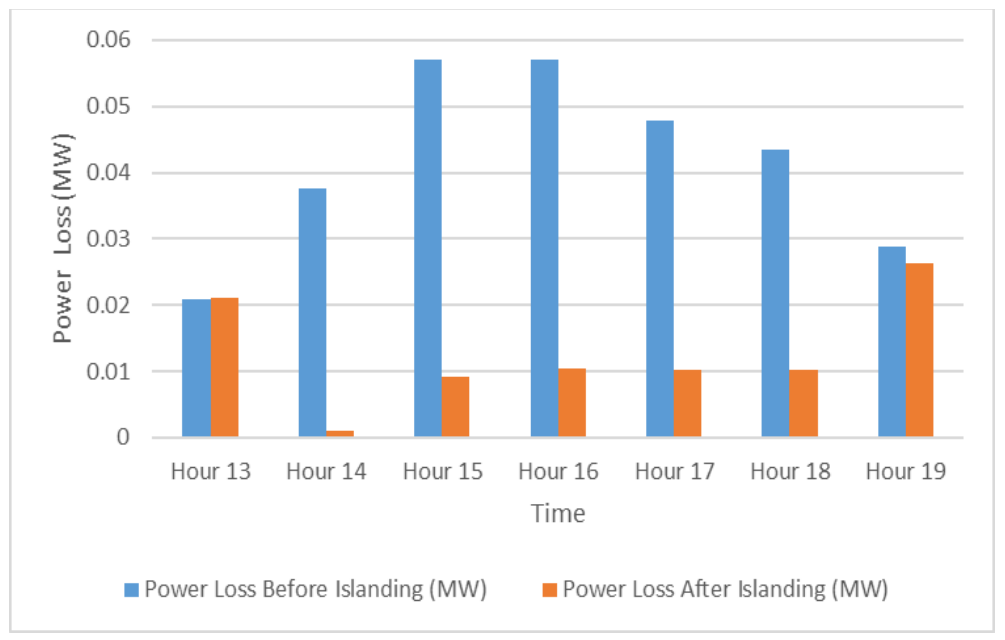

Figure 10. Comparison of losses in grid connected and islanding mode

When the renewable DGs power is sufficient along with one or two controlled DGs then others fuel type DGs can be taken out to serve the purpose of economical usage of fuel. It can be concluded that Proper selection of controllable DGs during islanding period have the optimal impacts on the restoration plan. The overall results of the proposed islanding based restoration are described in Tables 3-4.

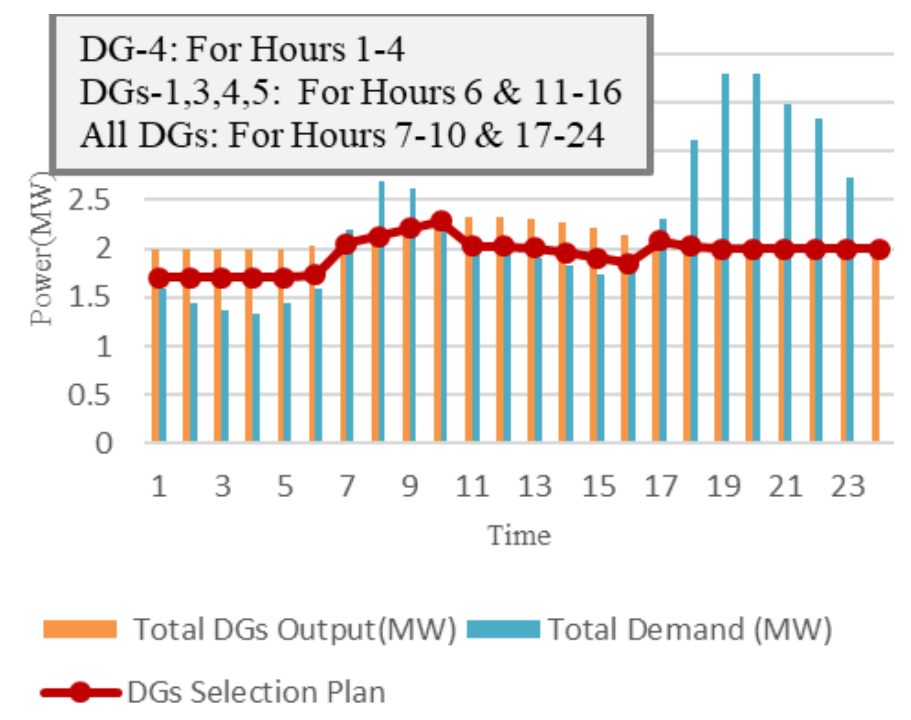

Figure 11. Economical DGs selection for 24 hours

Again at hour-19 of the islanding scheme, multiple faults were injected at nodes 2-3, 6-7 and 56-57. Purpose of injecting multiple faults was to analyze the behavior and performance of the proposed single islanding scheme under severe contingencies. Resulting MST in Figure12, shows that single island is formed with total loss of $0.003 \mathrm{MW}$ and $1.95 \mathrm{MW}$ of power restoration with generation capacity of $2 \mathrm{MW}$ during that hour. It can be concluded from these results 
that, the network under proposed islanded scheme is resilient and can respond and adapts quickly under severe situations.

Table 3. Case studies Result-1

\begin{tabular}{|c|c|c|c|c|c|c|c|}
\hline $\begin{array}{l}\text { Fault } \\
\text { Hours }\end{array}$ & $\begin{array}{c}\text { Generation } \\
\text { Capacity of } \\
\text { Hour } \\
\text { (MW) }\end{array}$ & $\begin{array}{l}\text { Total De- } \\
\text { mand of } \\
\text { Hour } \\
(\mathrm{MW})\end{array}$ & $\begin{array}{c}\text { Priority } \\
\text { Loads-1 Re- } \\
\text { stored } \\
(\mathrm{MW}, \%)\end{array}$ & $\begin{array}{c}\text { Priority } \\
\text { Loads-2 Re- } \\
\text { stored } \\
(\mathrm{MW}, \%)\end{array}$ & $\begin{array}{l}\text { Total Re- } \\
\text { stored } \\
\text { Load } \\
(\mathrm{MW})\end{array}$ & $\begin{array}{c}\text { Total Re- } \\
\text { stored } \\
\text { Load } \\
(\%)\end{array}$ & $\begin{array}{l}\text { Total } \\
\text { Load } \\
\text { Shed } \\
\text { (MW) }\end{array}$ \\
\hline 13 & 2.307 & 2.275 & $(0.2771), 100$ & $(0.3105), 100$ & 2.275 & 100 & 0 \\
\hline 14 & 2.2631 & 3.0582 & $(0.3725), 100$ & $(0.4174), 100$ & 2.0381 & 66.6 & 1.244 \\
\hline 15 & 2.2089 & 3.802 & $(0.45432), 100$ & $(0.47712), 93$ & 2.1985 & 57.82 & 1.531 \\
\hline 16 & 2.1459 & 3.802 & $(0.45432), 100$ & $(0.47112), 92.5$ & 2.141 & 56.31 & 1.5885 \\
\hline 17 & 2.0779 & 3.4331 & $(0.4179), 100$ & $(0.4683), 93$ & 2.0484 & 59.6 & 1.4404 \\
\hline 18 & 2.0226 & 3.282 & $(0.3998), 100$ & $(0.4480), 93$ & 1.9593 & 59.7 & 1.4404 \\
\hline 19 & 2 & 2.6852 & $0.3271,94.27$ & $0.3665,83.2$ & 1.9869 & 73.9 & 0.7434 \\
\hline
\end{tabular}

Table 3. Case studies Result-2

\begin{tabular}{|c|c|c|c|c|c|c|}
\hline Time (Hours) & Switch on & Switch off & $\begin{array}{c}\text { No of Iteration } \\
\text { for conver- } \\
\text { gence }\end{array}$ & $\begin{array}{l}\text { Time Taken } \\
\text { to converge }\end{array}$ & $\begin{array}{c}\text { Minimum } \\
\text { Voltage (p.u) }\end{array}$ & $\begin{array}{c}\text { Maximum } \\
\text { Voltage (p.u) }\end{array}$ \\
\hline 13 & $\begin{array}{l}11-43,15-46 \\
50-59,27-65\end{array}$ & None & 2 & 0.02 & 0.998916 & 1.000229 \\
\hline 14 & $\begin{array}{l}11-43,15-46 \\
50-59,27-65\end{array}$ & $60-61,61-62$ & 2 & 0.01 & 0.998931 & 1.000165 \\
\hline 15 & $\begin{array}{l}11-43,15-46 \\
50-59,27-65\end{array}$ & $\begin{array}{c}60-61,64-65 \\
68-69\end{array}$ & 2 & 0.01 & 0.998832 & 1.000142 \\
\hline 16 & $\begin{array}{l}11-43,15-46 \\
50-59,27-65\end{array}$ & $\begin{array}{c}32-33,60-61 \\
64-65\end{array}$ & 2 & 0.02 & 0.998977 & 1.000161 \\
\hline 17 & $\begin{array}{l}11-43,15-46 \\
50-59,27-65\end{array}$ & $60-61,64-65$ & 2 & 0.01 & 0.998876 & 1.000162 \\
\hline 18 & $\begin{array}{l}11-43,15-46 \\
50-59,27-65\end{array}$ & $60-61,64-65$ & 2 & 0.01 & 0.998898 & 1.000173 \\
\hline 19 & $\begin{array}{l}11-43,15-46 \\
50-59,27-65\end{array}$ & $3-28,47-48$ & 2 & 0.02 & 0.997733 & 1.000063 \\
\hline
\end{tabular}




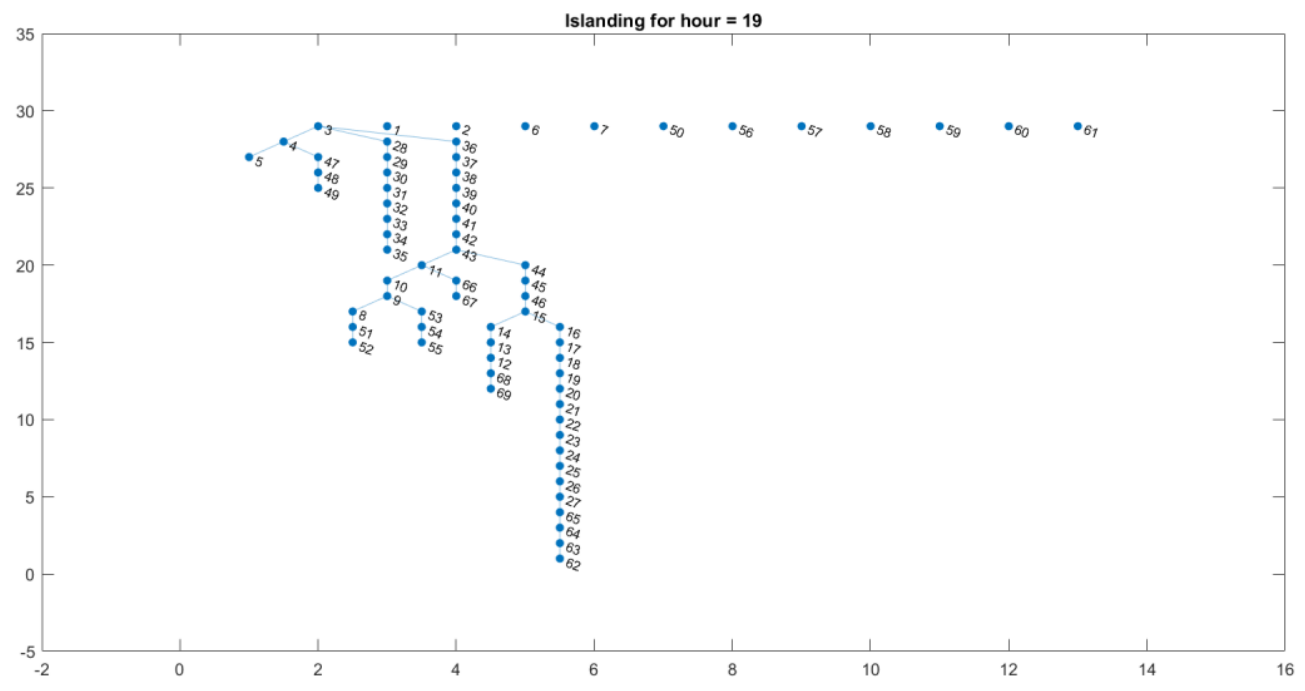

Figure 12. Economical DGs selection for 24 hours

\section{Comparisons}

In the past, various modern heuristic algorithms such as GA, Particle swarm optimization, MINLP model, and search-based approach using spanning-tree algorithm etc., have been used for service restoration in power systems. In this section, the performance of the proposed approach against the results of few of the previous islanding based restoration methods implemented on IEEE-69 bus system are compared.

In previous methods, the distribution system was split into several islands, with no or less DG merging resulting in some surplus DG capacity that could not be utilized due to island boundaries. According to the results of proposed study only one island is maintained throughout the restoration period. All of the DGs are merged and their power is utilized optimally. As a result no surplus power of the DGs in the island and load shedding is minimized. It can be observed from Figure 13 that using proposed adaptive technique, load shedding is reduced to $40 \%$, which is comparatively lower than the load shedding of the methods [38]-[41].In Figure 14, the minimum switching operation are compared, which also suggests that properly planning switching schemes during islanding period can not only minimize the load shedding but also reduces the losses. The losses in the island along with minimum voltage limits are shown in the Figure14. Stable voltage limits imply that the islanding system proposed in this paper not only ensures a high rate of restoration of the power supply, but also effectively eliminates the transient fluctuations of regular operating nodes when the power supply is restored and increases the reliability of the power distribution system's power supply. It is therefore concluded that the islanding system proposed in this paper can effectively improve the reliability and security of the power grid.

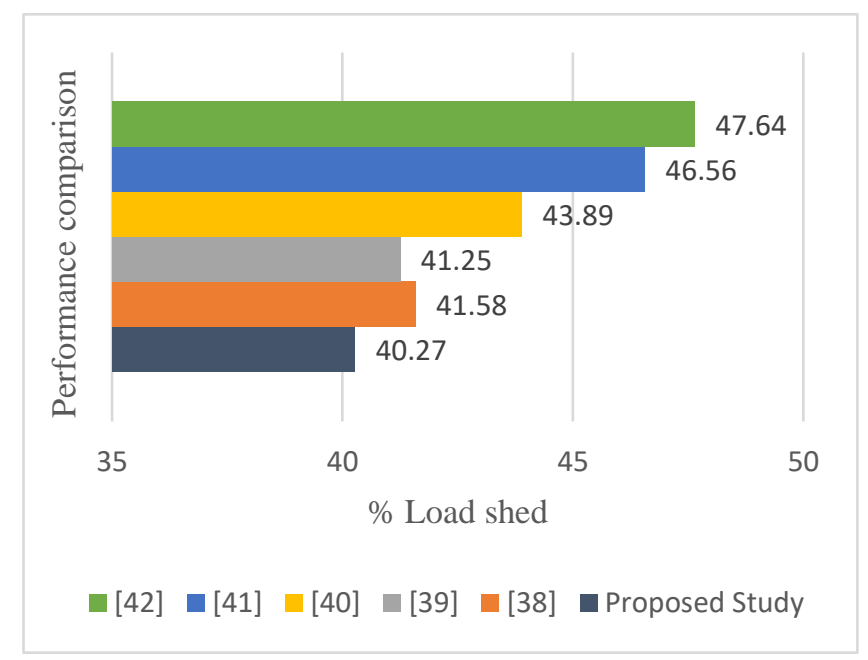

Figure 13. Load shedding comparison graph 


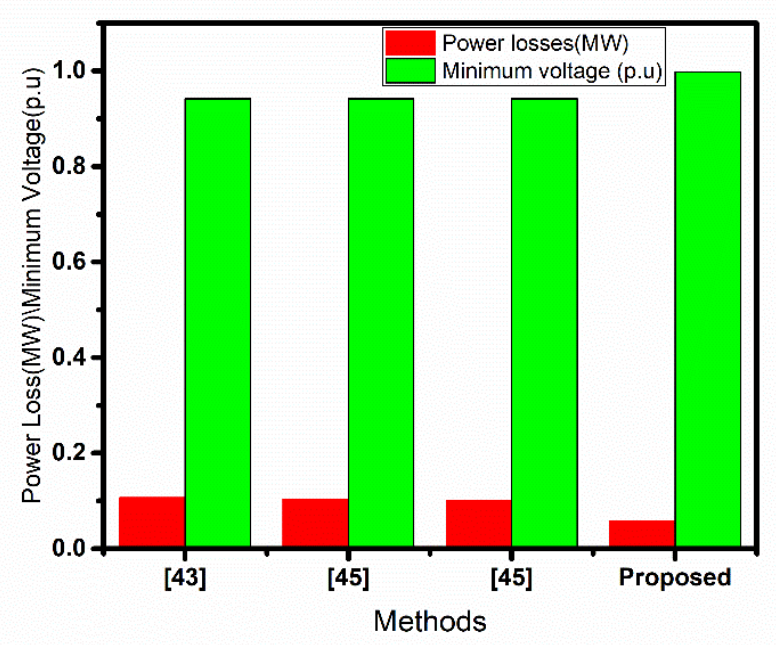

Figure 14. Power loss and switching comparison

\section{Conclusions}

The proposed method is implemented on the IEEE-69 bus system, which demonstrated the effectiveness of the restoration scheme. In this study islanding schemes are generated on hourly basis taking into account the variable load demands and uncertainty of renewable DGs. Initially, a single island is formed, which is then maintained throughout the restoration scheme, taking into account the changing behavior of the load requirements and the renewable DGs. A single island in which multiple DGs are coordinating by merging their powers to serve more loads and minimize load shedding. Furthermore, the severe situations are also addressed in when all three PV type DGs stopped sharing power due to evening hours of a day. This situation is effectively controlled by managing powers of remaining controlled type DGs using the proposed approach. Results of this contingency shows that the proposed method of islanding is more resilient and reliable and can withstand any sort of tough conditions, and islands can be well managed with the remaining DGs. Island not only adapts itself during load and DGs uncertainties but also manages its stability to withstand such severities. A plan for suitable selection of the DGs during islanding periods was presented to economize the fuel usage. The convergence time is very less and solution is obtained in very less iterations which is remarkable. Therefore the proposed algorithm is fast, reliable and can improve the power system's efficiency and resilience in severe situations. It can be said that the proposed single island-based restoration system fulfills the actual power system's operational requirements. In future controllable, uncontrollable loads and protection related issues along with the penetration of customer-owned DGs will be discussed.

Author Contributions: S.Kaka developed the idea and implemented the proposed scheme, and drafted the article, and Hussain.M provided useful comments and suggestions during the simulations and preparation of the first draft.

Funding: This research received no external funding.

Institutional Review Board Statement: This work was supported by the National Natural Science Foundation of China (No. 51677003).

Acknowledgments: This work was supported by the National Natural Science Foundation of China (No. 51677003).

Conflicts of Interest: The authors declare no conflict of interest.

\section{References}

1. Wang Y, Xu Y, He J. Using Multiple DGs for Distribution System Service Restoration after Extreme Events. 2018 IEEE Power Energy Soc. Gen. Meet., vol. 2018- Augus, IEEE; 2018, p. 1-5. https://doi.org/10.1109/PESGM.2018.8586500.

2. IEEE Standard Association. IEEE Std. 1547-2018. Standard for Interconnection and Interoperability of Distributed Energy Resources with Associated Electric Power Systems Interfaces. 2018. https://doi.org/10.1109/IEEESTD.2018.8332112.

3. A. Sharma, D. Srinivasan and A. Trivedi, "A Decentralized Multiagent System Approach for Service Restoration Using DG Islanding," in IEEE Transactions on Smart Grid, vol. 6, no. 6, pp. 2784-2793, Nov. 2015, doi: 10.1109/TSG.2015.2418334. 
4. C.-C. Liu, S. J. Lee, and S. Venkata, "An expert system operational aid for restoration and loss reduction of distribution systems," IEEE Trans. Power Syst. , vol. 3, no. 2, pp. 619-626, May 1988.

5. K. N. Miu, Hsiao-Dong Chiang and R. J. McNulty, "Multi-tier service restoration through network reconfiguration and capacitor control for large-scale radial distribution networks," Proceedings of the 21st International Conference on Power Industry Computer Applications. Connecting Utilities. PICA 99. To the Millennium and Beyond (Cat. No.99CH36351), Santa Clara, CA, USA, 1999, pp. 153-159, doi: 10.1109/PICA.1999.779398.

6. Y. Kumar, B. Das, and J. Sharma, "Service restoration in distribution system using non-dominated sorting genetic algorithm," Electr. Power Syst. Res., vol. 76, nos. 9/10, pp. 768-777, 2006.

7. Zhenkun Li, Xingying Chen, Kun Yu, Yi Sun and Haoming Liu, "A hybrid particle swarm optimization approach for distribution network reconfiguration problem," 2008 IEEE Power and Energy Society General Meeting - Conversion and Delivery of Electrical Energy in the 21st Century, Pittsburgh, PA, 2008, pp. 1-7, doi: 10.1109/PES.2008.4596635.

8. Jiansheng Lei, Youman Deng, Ying He and Boming Zhang, "Network reconfiguration in unbalanced distribution systems for service restoration and loss reduction," 2000 IEEE Power Engineering Society Winter Meeting. Conference Proceedings (Cat. No.00CH37077), Singapore, 2000, pp. 2345-2350 vol.4, doi: 10.1109/PESW.2000.847175.

9. S. Khushalani, J. M. Solanki and N. N. Schulz, "Optimized Restoration of Unbalanced Distribution Systems," in IEEE Transactions on Power Systems, vol. 22, no. 2, pp. 624-630, May 2007, doi: 10.1109/TPWRS.2007.894866.

10. Z. Wang and J. Wang, "Self-Healing Resilient Distribution Systems Based on Sectionalization Into Microgrids," in IEEE Transactions on Power Systems, vol. 30, no. 6, pp. 3139-3149, Nov. 2015, doi: 10.1109/TPWRS.2015.2389753.

11. J. Li, X. Ma, C. Liu and K. P. Schneider, "Distribution System Restoration With Microgrids Using Spanning Tree Search," in IEEE Transactions on Power Systems, vol. 29, no. 6, pp. 3021-3029, Nov. 2014, doi: 10.1109/TPWRS.2014.2312424.

12. H. Gao, Y. Chen, Y. Xu and C. Liu, "Resilience-Oriented Critical Load Restoration Using Microgrids in Distribution Systems," in IEEE Transactions on Smart Grid, vol. 7, no. 6, pp. 2837-2848, Nov. 2016, doi: 10.1109/TSG.2016.2550625.

13. C. Chen, J. Wang, F. Qiu and D. Zhao, "Resilient Distribution System by Microgrids Formation After Natural Disasters," in IEEE Transactions on Smart Grid, vol. 7, no. 2, pp. 958-966, March 2016, doi: 10.1109/TSG.2015.2429653.

14. M. Ahmadi, M. E. Lotfy, A. M. Howlader, A. Yona, and T. Senjyu, "Centralized multi-objective integration of wind farm and battery energy storage system in real-distribution network considering environmental, technical and economic perspective," IET Gener., Transmiss. Distrib.,vol. 13, no. 22, pp. 5207-5217, 2019.

15. B. Chen, C. Chen, J. Wang and K. L. Butler-Purry, "Multi-Time Step Service Restoration for Advanced Distribution Systems and Microgrids," in IEEE Transactions on Smart Grid, vol. 9, no. 6, pp. 6793-6805, Nov. 2018, doi: 10.1109/TSG.2017.2723798.

16. S. Poudel and A. Dubey, "Critical Load Restoration Using Distributed Energy Resources for Resilient Power Distribution System," in IEEE Transactions on Power Systems, vol. 34, no. 1, pp. 52-63, Jan. 2019, doi: 10.1109/TPWRS.2018.2860256.

17. Ding T, Lin Y, Bie Z, Chen C. A resilient microgrid formation strategy for load restoration considering master-slave distributed generators and topology reconfiguration. Appl Energy 2017;199:205-16. https://doi.org/10.1016/j.apenergy.2017.05.012.

18. M. Hussain, X. Wu, S. Kaka, Y. Xu and S. Wang, "A Multi-Agent based Critical Load Restoration Using Islanded Operation of DGs in Radial Distribution Network," 2019 IEEE 3rd International Electrical and Energy Conference (CIEEC), Beijing, China, 2019, pp. 293-297, doi: 10.1109/CIEEC47146.2019.CIEEC-2019145.

19. C. Lee, C. Liu, S. Mehrotra and Z. Bie, "Robust Distribution Network Reconfiguration," in IEEE Transactions on Smart Grid, vol. 6, no. 2, pp. 836-842, March 2015, doi: 10.1109/TSG.2014.2375160.

20. Bai, X.; Mavrocostanti, Y.; Strickland, D.; Harrap, C. Distribution network reconfiguration validation with uncertain loadsnetwork configuration determination and application. IET Gener. Transm. Distrib. 2016, 10, 2852-2860.

21. Zhang, P.; Li, W.Y.; Wang, S.X. Reliability-oriented distribution network reconfiguration considering uncertainties of data by interval analysis. Int. J. Electr. Power Energy Syst. 2012, 34, 138-144.

22. J. Muñoz, C. Cañizares, K. Bhattacharya and A. Vaccaro, "Affine arithmetic based methods for voltage and transient stability assessment of power systems with intermittent generation sources," 2013 IREP Symposium Bulk Power System Dynamics and Control - IX Optimization, Security and Control of the Emerging Power Grid, Rethymno, 2013, pp. 1-12, doi: 10.1109/IREP.2013.6629363.

23. A. Vaccaro, C. A. Cañizares and K. Bhattacharya, "A Range Arithmetic-Based Optimization Model for Power Flow Analysis Under Interval Uncertainty," in IEEE Transactions on Power Systems, vol. 28, no. 2, pp. 1179-1186, May 2013, doi: 10.1109/TPWRS.2012.2214405.

24. C. Rakpenthai, S. Uatrongit and S. Premrudeepreechacharn, "State estimation of power system considering network parameter uncertainty based on parametric interval linear systems," PES T\&D 2012, Orlando, FL, 2012, pp. 1-1, doi: 10.1109/TDC.2012.6281424.

25. Oboudi, M. H., Hooshmand, R.-A., \& Rahimi, S. (2020). Stochastic Operation Framework of Microgrid under Uncertainties of Load, Generation, and Contingency. Journal of Energy Engineering, 146(1), 04019037. https://doi.org/10.1061/(ASCE)EY.19437897.0000639.

26. ZHU J, GU W, JIANG P, WU Z, YUAN X, NIE Y. Integrated approach for optimal island partition and power dispatch. J Mod Power Syst Clean Energy 2018;6:449-62. https://doi.org/10.1007/s40565-017-0314-z.

27. S. H. Lee, G. Son and J. Park, "Power Management and Control for Grid-Connected DGs With Intentional Islanding Operation of Inverter," in IEEE Transactions on Power Systems, vol. 28, no. 2, pp. 1235-1244, May 2013, doi: 10.1109/TPWRS.2012.2209686.

28. A. Khodaei, "Resiliency-Oriented Microgrid Optimal Scheduling," in IEEE Transactions on Smart Grid, vol. 5, no. 4, pp. 15841591, July 2014, doi: 10.1109/TSG.2014.2311465. 
29. S. Ahn, S. Nam, J. Choi and S. Moon, "Power Scheduling of Distributed Generators for Economic and Stable Operation of a Microgrid," in IEEE Transactions on Smart Grid, vol. 4, no. 1, pp. 398-405, March 2013, doi: 10.1109/TSG.2012.2233773. A. Khodaei, "Resiliency-Oriented Microgrid Optimal Scheduling," in IEEE Transactions on Smart Grid, vol. 5, no. 4, pp. 1584-1591, July 2014, doi: 10.1109/TSG.2014.2311465.

30. D. T. Power Restoration in Distribution Network Using MST Algorithms. New Front. Graph Theory, InTech; 2012. https://doi.org/10.5772/35897.

31. K. Sanaullah, M. Xia, M. Hussain, S. Hussain and A. Tahir, "Optimal islanding for restoration of power distribution system using Prim's MST algorithm," in CSEE Journal of Power and Energy Systems, doi: 10.17775/CSEEJPES.2020.01580.

32. Arnaout M, Rammal R, Abdulnabi S. Electric Power System Simulator Tool in MATLAB. Sci. Educ. - Res. New Technol., InTech; 2017. https://doi.org/10.5772/intechopen.68955.

33. H. Ahmadi and J. R. Martí, "Mathematical representation of radiality constraint in distribution system reconfiguration problem," Int. J. Electr. Power Energy Syst., vol. 64, pp. 293-299, Jan. 2015, doi: 10.1016/j.ijepes.2014.06.076.

34. M. E. Baran and F. F. Wu, "Optimal capacitor placement on radial distribution systems," in IEEE Transactions on Power Delivery, vol. 4, no. 1, pp. 725-734, Jan. 1989, doi: 10.1109/61.19265.

35. T. Ouyang, Y. He, H. Li, Z. Sun and S. Baek, "Modeling and Forecasting Short-Term Power Load With Copula Model and Deep Belief Network," in IEEE Transactions on Emerging Topics in Computational Intelligence, vol. 3, no. 2, pp. 127-136, April 2019, doi: 10.1109/TETCI.2018.2880511.

36. https://PVwatts.nrel.gov/PVwatts.php.

37. Xu G, Wu S, Tan Y. Island Partition of Distribution System with Distributed Generators Considering Protection of Vulnerable Nodes. Appl Sci 2017; 7:1057. https://doi.org/10.3390/app7101057.

38. Zhang H, Peng M, Wu H, Zhu L, Che H, Liu Z. A strategy for intentional islanding of distribution networks based on node electrical relevance and artificial bee colony algorithm. IEEJ Trans Electr Electron Eng 2018;13:84-91. https://doi.org/10.1002/tee.22501.

39. F. Wang et al., "A Multi-Stage Restoration Method for Medium-Voltage Distribution System With DGs," in IEEE Transactions on Smart Grid, vol. 8, no. 6, pp. 2627-2636, Nov. 2017, doi: 10.1109/TSG.2016.2532348.

40. Bai, X.; Mavrocostanti, Y.; Strickland, D.; Harrap, C. Distribution network reconfiguration validation with uncertain loadsnetwork configuration determination and application. IET Gener. Transm. Distrib. 2016, 10, 2852-2860.

41. Jikeng L, Xudong W, Peng W, Shengwen L, Guang-hui S, Xin M, et al. Two-stage method for optimal island partition of distribution system with distributed generations. IET Gener Transm Distrib 2012;6:218. https://doi.org/10.1049/iet-gtd.2010.0812.

42. Ding Lei, Pan Zhen-cun, Cong Wei, Gao Guang-ling. Rooted tree based searching strategies for intentional islanding of distributed generation. IET 9th Int. Conf. Dev. Power Syst. Prot. (DPSP 2008), vol. 2008, IEE; 2008 , p. 302-7. https://doi.org/10.1049/cp:20080054.

43. A. Tandon and D. Saxena, "A comparative analysis of SPSO and BPSO for power loss minimization in distribution system using network reconfiguration," 2014 Innovative Applications of Computational Intelligence on Power, Energy and Controls with their impact on Humanity (CIPECH), Ghaziabad, 2014, pp. 226-232, doi: 10.1109/CIPECH.2014.7019093.

44. S. Jena and S. Chauhan, "Solving distribution feeder reconfiguration and concurrent dg installation problems for power loss minimization by multi swarm cooperative PSO algorithm," 2016 IEEE/PES Transmission and Distribution Conference and Exposition (T\&D), Dallas, TX, 2016, pp. 1-9, doi: 10.1109/TDC.2016.7520021.

45. I. I. Atteya, H. Ashour, N. Fahmi and D. Strickland, "Radial distribution network reconfiguration for power losses reduction using a modified particle swarm optimisation," in CIRED - Open Access Proceedings Journal, vol. 2017, no. 1, pp. 2505-2508, 10 2017, doi: 10.1049/oap-cired.2017.1286. 